Bond University

Research Repository

\title{
Could habits hold the key to weight loss maintenance? A narrative review
}

Cleo, G.; Isenring, E.; Thomas, R.; Glasziou, P.

Published in:

Journal of Human Nutrition and Dietetics

DOI:

10.1111/jhn.12456

Licence:

Unspecified

Link to output in Bond University research repository.

Recommended citation(APA):

Cleo, G., Isenring, E., Thomas, R., \& Glasziou, P. (2017). Could habits hold the key to weight loss maintenance? A narrative review. Journal of Human Nutrition and Dietetics, 30(5), 655-664. https://doi.org/10.1111/jhn.12456

\footnotetext{
General rights

Copyright and moral rights for the publications made accessible in the public portal are retained by the authors and/or other copyright owners and it is a condition of accessing publications that users recognise and abide by the legal requirements associated with these rights.
}

For more information, or if you believe that this document breaches copyright, please contact the Bond University research repository coordinator. 


\title{
Could habits hold the key to weight loss maintenance? A narrative review
}

\author{
G. Cleo, ${ }^{1,2}$ E. Isenring, ${ }^{\prime}$ R. Thomas ${ }^{1,2}$ \& P. Glasziou ${ }^{12}$ \\ 'Faculty of Health Sciences and Medicine, Bond University, Gold Coast, QLD, Australia \\ ${ }^{2}$ Centre for Research in Evidence-Based Practice (CREBP), Bond University, Gold Coast, QLD, Australia
}

\begin{abstract}
:
Background: Despite the significance placed on lifestyle interventions for obesity management, most weight loss is followed by a weight regain. Psychological concepts of habitual behaviour and automaticity have been suggested as plausible explanations for this overwhelming lack of long-term weight loss success. Interventions, which focus on changing an individual's behaviour, are not usually successful at changing an individual's habits, as they do not incorporate the strategies required to break unhealthy habits and/or form new healthy habits.
\end{abstract}

Methods: A narrative review was conducted and describes the theory behind habit formation in relation to weight regain, and evaluated the effectiveness of using habits as tools to maintain weight loss. Three specific habit-based weight loss programs are described: '10 Top Tips', 'Do Something Different' and 'Transforming Your Life'.

Results: Participants in these interventions achieved significant weight loss when compared with a control group or other conventional interventions.

Conclusion: Habit-based interventions show promising results in sustaining behaviour change. Weight loss maintenance may benefit from incorporating habit-focused strategies and should be investigated further.

Keywords: habit-based intervention, habits, obesity, overweight, weight maintenance.

Correspondence

G. Cleo, Bond Institute of Health and Sport, Faculty of Health Sciences and Medicine, Bond University, Robina, QLD 4226, Australia.

Tel.: +61 755953037

E-mail: gcleo@bond.edu.au
How to cite this article

Cleo G., Isenring E., Thomas R., Glasziou P. (2017) Could habits hold the key to weight loss maintenance? A narrative review. J Hum Nutr Diet.

doi: $10.1111 /$ jhn.12456 


\section{Introduction}

\section{Weight loss maintenance}

In Obesity, even modest weight loss is associated with significant health benefits, especially when maintained over time ('). A systematic review and meta-analysis of 26 randomised controlled trials $(N=2899$ participants) reported a 5-10\% reduction in body weight in overweight or obese individuals was associated with significant improvements in LDL cholesterol, total cholesterol, blood pressure, blood glucose and other health indices (2.3). If the lost weight is not regained, these health benefits appear to be sustained $\left(^{(}\right)$. Weight loss of 10$15 \%$ body weight has even greater benefits $\left({ }^{(}\right)$. Achieving ideal weight is not essential for an individual to attain these health benefits $\left(^{\circ}\right)$.

Among participants from the National Weight Control Registry (NWCR) who have maintained their weight loss for a number of years $(N=784)$, over $90 \%$ reported improvement in their overall quality of life, mobility, level of energy, general mood and self-confidence ( $\left.{ }^{(}\right)$. Furthermore, a randomised controlled trial of 588 overweight or obese individuals reported reductions in weight at 12 months were associated with improvements in overall wellbeing, depression, anxiety, and ratings of self-control and vitality $\left({ }^{8}\right)$. These findings are consistent with previous studies, which investigated the impact of weight change on various factors relating to quality of life $\left(^{\circ}\right)$. A cross-sectional longitudinal study $(N=4601)$ showed a significant association between excess weight and lower quality of life scores $\left.{ }^{10}\right)$ and a randomised, parallel group trial of 423 participants showed predictability between lower weight and better quality of life regardless of the weight loss intervention (").

The first 2-5 years after weight loss is the most vulnerable time for weight regain. Maintaining weight loss during those first few years decreases the risk of successive regain by $50 \%$ ('). Consequently, individuals who manage to maintain their weight loss for more than 2 years have a significantly greater chance of keeping the weight off long-term ( $)$. However, considering the majority of overweight or obese individuals will regain most of the weight lost, understanding and addressing the determinants for weight regain is essential for successful weight loss maintenance interventions. No single theory can fully explain decision making in health behaviour, therefore, considering multiple perspectives is essential (13).

\section{Conventional interventions and outcomes}

A wide range of interventions are available for treating overweight and obesity. These can be classified into three general categories: surgical, pharmacological and lifestyle.

Bariatric surgery has seen the most success with weight loss maintenance $\left({ }^{14}\right)$. However only a small number of individuals qualify for surgical interventions due to guideline recommendations that surgical candidates have a body mass index (BMI) of at least $40 \mathrm{~kg} / \mathrm{m}^{2}$ or a BMI between $35-39 \mathrm{~kg} / \mathrm{m}^{2}$ and experiencing at least one serious obesity-related comorbidity. These guidelines are due to the significant risk of morbidity and mortality associated with bariatric surgery ('). 
Pharmacotherapy treatment (such as prescription medication which supress appetite or inhibit fat absorption) is generally prescribed for no longer than 12 weeks due to adverse side effects such as insomnia, dizziness, headaches, stomach aches and an increased risk of heart disease and stroke (is). Consequently pharmacotherapy studies show a general short-term weight reduction and an invariable weight regain due to the short treatment period $\left({ }^{14}\right)$.

Finally, lifestyle interventions (which constitute the foundation of any weight-management program) present a consistent regain of the weight lost with about $40 \%$ regained over the first year following treatment and much of the rest over the following three years $\left({ }^{1}{ }^{14}\right)$. Understanding and addressing the determinants for weight regain in lifestyle interventions is therefore essential for successful weight loss maintenance interventions.

There is extensive evidence that behaviour can be effectively modified through behaviour change interventions, however evidence for the sustainability of this change is limited ('6). Simply knowing what diet and exercise behaviours are necessary for long-term weight loss success does not equate to a healthy diet or loss of weight. In recent years, studies in psychology have shown strong evidence to suggest that unconscious, automatic processes strongly influence our behaviour ${ }^{17}$ ). This evidence of unconscious behaviour and automaticity has led to extensive research in the area of habits, the intention-behaviour gap, automaticity and behavioural flexibility. We discuss the theory of these novel determinants, search for weightloss interventions that use these behaviour change techniques, and evaluate the effectiveness of using these techniques as tools to maintain weight loss in adults.

\section{Habits}

According to a systematic review of 100 theoretical explanations for maintenance of behaviour change, the brief theoretical explanation for a habit is when someone is effective in maintaining behaviours which have become habitual and are supported by automatic responses to relevant cues $\left({ }^{16}\right)$.

Habits are generally formed by repeating a behaviour until it has become more or less automatic $\left.{ }^{18}\right)$. By repeating behaviour in a consistent context, we forge a direct link in memory between the context and response $\left(^{19}\right)$. Therefore, we learn to associate the behaviour triggered by that setting; this process is termed 'context-dependent repetition'. This reinforces a mental contextbehaviour association, such that alternative options become less accessible in memory ${ }^{(2)}$; eventually, the mere perception of the context automatically triggers the responding behaviour $\left.{ }^{21,22}\right)$. Habit formation involves a gradual shift in cognitive control from intentional to automatic processes $\left.{ }^{18}\right)$. This is why a habit is defined as an action which has been triggered automatically in response to a contextual cue associated with its performance ${ }^{23}$ ). Approximately $45 \%$ of everyday behaviours are repeated in the same location ${ }^{24,25}$. Daily life consistently exposes people to numerous cues triggering wanted and unwanted habits.

To illustrate habit formation and how it relates to dietary intake, imagine that each time a person goes home in the evening, they eat a snack. When they first eat the snack, a mental link is formed between the context (getting home) and their response to that context (eating a snack). 
Every time they subsequently snack in response to getting home, this link strengths, to the point that getting home prompts them to eat a snack automatically; a habit has been formed ${ }^{(23}$ ).

We make over 200 food decisions per day ${ }^{\left({ }^{2}\right)}$. Most of these decisions appear to be 'automatic' or habitual, which means we unconsciously eat without reflection, deliberation or any sense of awareness of what or how much food we select and consume $\left.{ }^{26023}\right)$. Therefore, due to the lack of thought required to perform a habit, habitual behaviours override intention ${ }^{(28)}$. The sight of the TV remote control can derail a plan to exercise; the notification of a new email can trigger the common habit of procrastinating on the internet ${ }^{22}$ ). The ubiquitous effect of habits in everyday behaviour is a key to understanding the struggle people recurrently experience in changing their lifestyles. Failed attempts at changing diet and exercise behaviour are typical $\left(^{8}\right)$. Such failures are common considering cues such as location and time of day both trigger repetition of usual responses ${ }^{22}$ ). Lack of will power or poor knowledge of health is not necessarily an indicator for failures to change, but instead may indicate the power of situations to trigger past responses. Although people are free to act in non-habitual ways, everyday demands such as time pressures and distractions reduce the capacity to engage in reflective thought; therefore people tend to rely on eating habits $\left(^{29}\right)$. In a qualitative investigation of 11 adults, automatic behaviour patterns were identified as a perceived cause of weight gain $\left.{ }^{(30}\right)$. Habits keep us operating in the way we have always done, despite our best intentions to act otherwise.

\section{Intention-behaviour gap}

Social psychology theories suggest that forming a goal intention (e.g. 'I intend to eat healthily') is imperative in promoting behaviour change and goal attainment $\left(^{31}\right)$. However, a recent metaanalysis ( $N=22$ studies) of healthy eating and physical activity habits showed that the stronger an individual's habit strength, the less impact their intentions had on their actions $\left.{ }^{(32}\right)$. Although individuals develop an intention to change their health behaviour, they might not take any action; this discrepancy is called the "intention-behaviour gap" $\left.{ }^{{ }^{3}}\right)$. A cross-sectional study $(N=$ 538) integrated habit strength in the theory of planned behaviour in order to understand participants' fruit consumption. Findings showed that stronger fruit consumption habits made fruit consumption less intentional ${ }^{\left({ }^{35}\right)}$. Therefore participants with strong habits of fruit consumption ate fruit as a result of their habit to do so, not their intention. In fact, when an individual had low levels of habit strength the intention-fruit consumption relationship was more than twice as strong than when an individual had a high level of habit strength ${ }^{35}$ ).

The same participants were assessed for exercise behaviour, intention and habit strength. Findings indicated that exercise has both a cognitive and an automatic component and that stronger exercise habits make exercise less intentional, with the intention-exercise relationship nearly three times stronger at lower levels of exercise habit strength than at higher levels $\left(^{35}\right)$.

Habits are strengthened as behaviour is repeatedly performed in a consistent context $\left({ }^{32}\right)$ and when behaviour is reinforced by a pleasant experience or reward (i.e. the sweet satisfaction of a chocolate cookie or the comfort of a hearty, warm pudding) ${ }^{\left({ }^{36}\right)}$. In a three-wave observational 
study of fruit and vegetable $(\mathrm{FV})$ intake in adults $(N=127)$, the researchers hypothesised that the intrinsic reward value of FV consumption would strengthen FV consumption habits. Habit strength was assessed with the Self-Report Behavioural Automaticity Index (SRBAI), an automaticity-specific abbreviation of the Self-Report Habit Index (SRHI) ( ${ }^{37}$ ). Questionnaires measured participants' intrinsic reward, intention and self-efficacy at baseline and after two and four weeks. Results indicated intrinsic reward had a positive indirect effect on habit strength through its influence on the frequency of FV consumption. Further, the relationship between FV consumption and habit was stronger where consumption was considered more intrinsically rewarding. These findings highlight the potential relevance of intrinsic reward to habit and should be considered as a tool in habit-based interventions $\left.{ }^{(38}\right)$.

People with strong habits are generally not observant to information about the adverse effects of their behaviour $\left.{ }^{36}\right)$. To illustrate, Ji and Wood studied college students $(N=219)$ over a weeklong period and predicted how often they watched TV or purchased fast food from their behavioural intentions and from their habits ${ }^{\left({ }^{9}\right)}$. The findings showed that students acted on their intentions only when their habit strength was weak or moderate $\left(^{(3)}\right.$. Students with strong habits continued their typical behaviour in purchasing fast food, despite their intentions. Therefore, as habit strength increased, intentional behaviour decreased. In fact, intentions guided actions largely when habits had not been formed. These findings support the theory that habitual behaviour can be triggered independent of an individual's intentions ( $\left(^{(9)}\right.$. Consequently, this automatic eating behaviour has been described as the most plausible factor to explain the lack of weight loss maintenance success $\left({ }^{40}\right)$.

\section{Automaticity}

Once a habit is formed, automaticity is considered to be the 'active ingredient' of that habit $\left.{ }^{18}\right)$. Automaticity can be described as a behaviour which features efficiency, lack of awareness, unintentionality and uncontrollability $\left({ }^{4}\right)$. Automatic behaviours occur without reflective decision-making processes, $\left.{ }^{(27}\right)$ and increase with continuous repetition of the behaviour $\left.{ }^{41}\right)$.

The complexity of a particular behaviour impacts the development and strength of automaticity $(2,41)$. In a study of 96 participants who chose an eating, drinking or exercise behaviour to carry out daily in the same context for 12 weeks, the average time participants took to reach automaticity of their chosen behaviour was 66 days, (range of 18-254 days) ${ }^{32}$ ). Exercise behaviours (considered more complex than eating or drinking) took one and a half times longer to reach a level of automaticity than eating and drinking habits ) ( ${ }^{(1)}$. In another study, automaticity strength peaked more rapidly for simple actions (e.g. drinking water) than for more elaborate procedures (e.g. doing 50 sit-ups) ${ }^{(23}$ ). Other studies report consistent findings with participants automatically performing lifestyle behaviours after approximately 10 weeks; moreover, participants maintained their new habitual behaviours over 32 weeks and the behaviours increased in automaticity ${ }^{\left({ }^{2}\right.}$ ).

Automaticity is a powerful tool in positive habit formation as there is a reassurance that doing a new and healthful behaviour will get progressively easier. Therefore, maintaining motivation 
and consistently undertaking the new behaviour is only necessary until the habit forms and the new behaviour becomes 'second nature' ${ }^{23}$. Lifestyle changes commonly last only a short period of time as individuals generally return to their previous patterns $\left({ }^{43}\right)$. Once a behaviour becomes automatic however, it is more resilient to change than purposeful or intentional behaviours $\left({ }^{41,44}\right)$ and therefore lasts longer and achieves continued or maintained results $\left({ }^{45}\right)$.

Habit advice, should therefore include behaviour changes which are simple for individuals to implement as this provides realistic long-term effects $\left.{ }^{\left({ }^{23}\right.}\right)$. Gardner et al. developed a sample tool for health professionals to use with patients in order to encourage habit formation (Box 1).

Box 1 A tool for patients to encourage habit formation (2)

\section{Box 1. A tool for patients}

\section{Make a new healthy habit}

1. Decide on a goal that you would like to achieve for your health.

2. Choose a simple action that will get you towards your goal which you can do on a daily basis.

3. Plan when and where you will do your chosen action. Be consistent: choose a time and place that you encounter every day of the week.

4. Every time you encounter that time and place, do the action.

5. It will get easier with time, and within 10 weeks you should find you are doing it automatically without even having to think about it.

6. Congratulations, you ve made a healthy habit!

My goal le.g. 'to eat more fruit and vegetables']

My plan (e.g. 'after I have lunch at home I will have a piece of fruit')

(When and where] I will

Some people find it helpful to keep a record while they are forming a new habit. This daily tick-sheet can be used until your new habit becomes automatic. You can rate how automatic it feels at the end of each week. to watch it getting easier.

\begin{tabular}{|c|c|c|c|c|c|c|c|c|c|c|}
\hline & Week 1 & Week 2 & Week 3 & Week 4 & Week 5 & Week 6 & Week 7 & Week 8 & Week 9 & Week 10 \\
\hline \multicolumn{11}{|l|}{ Monday } \\
\hline \multicolumn{11}{|l|}{ Tuesday } \\
\hline \multicolumn{11}{|l|}{ Wednesday } \\
\hline \multicolumn{11}{|l|}{ Thursday } \\
\hline \multicolumn{11}{|l|}{ Friday } \\
\hline \multicolumn{11}{|l|}{ Saturday } \\
\hline \multicolumn{11}{|l|}{ Sunday } \\
\hline \multicolumn{11}{|l|}{$\begin{array}{l}\text { Done on } \\
>5 \text { days, } \\
\text { yes or no }\end{array}$} \\
\hline $\begin{array}{l}\text { How } \\
\text { automatic } \\
\text { does it feel? } \\
\text { Rate from } \\
1 \text { [not at all] } \\
\text { to10 } \\
\text { (completely) }\end{array}$ & & & & & & & & & & \\
\hline
\end{tabular}


Habit formation begins with an 'initiation phase', during which the new chosen behaviour and the context in which that behaviour will be performed are selected; for example, 'eating a piece of fruit at breakfast'. Automaticity develops in the subsequent 'learning phase', during which the behaviour is repeated in the chosen context to strengthen the context-behaviour association (self-monitoring through a tick sheet may help $\left({ }^{46}\right)$ [Box 1]). Finally, habit formation is accomplished in the 'stability phase', at which the behaviour persists over time with minimal conscious thought or effort $\left.{ }^{(23}\right)$. This tool has not been formally tested, however synthesises evidence based on current literature of habit theory $\left.{ }^{(23}\right)$.

\section{Behavioural flexibility}

Behavioural flexibility has an inverse relationship to automaticity and is a measure of a person's range of behaviours across different situations $\left({ }^{47}\right)$. An individual with more behavioural flexibility has a greater behavioural reservoir and behaves in less habitual ways than a person with less behavioural flexibility. Behavioural flexibility is primarily measured using a psychometric instrument labelled the 'FIT Profiler' (Framework for Internal Transformation) ${ }^{47.52}$ ) which measures core aspects of a person's thinking processes and the nature and flexibility of their behaviours.

In a study sampling over 1,000 people, behavioural flexibility was found to correlate negatively and significantly with BMI ( $\left.{ }^{4}\right)$. This finding led the researchers to the novel hypothesis that, if behavioural flexibility is negatively correlated with BMI, then increasing behavioural flexibility would lead to weight reduction $\left({ }^{\left({ }^{\circ}\right.}\right)$. By doing something different on a daily basis individuals are challenged to break existing habits and increase their behavioural flexibility. This approach avoids the need for sustained willpower and may provide the impetus for positive change by altering the daily habits that trigger overeating and the broader changes needed for positive health behaviour generally ${ }^{(4)}$ ).

\section{Habit change interventions for weight loss maintenance}

Breaking unwanted habits can be achieved through restructuring an individual's environment, or programming new responses to their existing environment ( ${ }^{32}$. Interventions, which focus on changing an individual's behaviour are not usually successful at changing an individual's habits as they do not incorporate the strategies required to break unwanted habits and form new healthful habits ${ }^{(2,53)}$. General health advice is usually based on advising patients on what to change and why (e.g reduce daily calorie intake to achieve weight loss). Such advice requires conscious, deliberative thoughts $\left.{ }^{(23}\right)$. However, motivation and attention to change behaviours wane over time, therefore the effects of behaviour change are typically short-lived ( $\left.{ }^{23}\right)$. Advice on how to change, whilst engaging automatic behaviours (including efficiency, lack of awareness, unintentionality and uncontrollability ( $\left.{ }^{41}\right)$ may offer a valuable alternative with potential for long-term impact ${ }^{23}$ ).

A focused search in PubMed for its generality and PsychInfo for its focus on psychological interventions found three habit-based weight loss interventions: '10 Top Tips' $(44,47)$, 'Do 
Something Different' $\left.{ }^{47,40}\right)$ and 'Transforming Your Life' $\left({ }^{54,55}\right)$. See Table 1 for comparison of intervention methods.

The 10 Top Tips (10TT) is an intervention based on habit formation theory, using written materials to guide participants through a set of simple weight management behaviours with the intention of making those behaviours habitual. For example, participants are required to keep to a meal routine, eat off a smaller plate, eat mindfully and pack a healthy snack. Results from a randomised controlled trial with 104 overweight or obese participants, showed the 10TT intervention produced a statistically significant mean weight loss of $2.0 \mathrm{~kg}$ at 8 weeks compared to a mean weight loss of $0.4 \mathrm{~kg}$ in the control group. Moreover, participants in the 10TT intervention continued to lose weight with an average of weight loss of $3.8 \mathrm{~kg}$ at 32 weeks. The intervention was easily disseminated, low-cost and produced clinically significant weight loss. Participants in the 10TT study also reported automaticity of some of the healthy habits prescribed in the intervention, therefore sustainability of their weight loss was predicted ${ }^{(2)}$ ).

Semi-structured interviews were conducted at the end of the intervention with a random subsample $(N=10)$ of participants in order to gather feedback and explore general experiences. Results showed that behaviour change was initially experienced as cognitively effortful but as automaticity increased, enactment became easier. Most participants reported characteristics of habit: Automaticity, the importance of repetition and "feeling strange" when not doing the behaviour ${ }^{(5)}$.

Do Something Different (DSD) is a behavioural intervention, which focuses on increasing participants' behavioural flexibility by breaking daily habits. The authors describe the aim of DSD is to break the distal habits proposed to play a role in unhealthy dietary and exercise behaviours. DSD requires participants to do something different each day and to engage in novel, weekly activities to expand their behavioural repertoire. What makes this intervention particularly novel is that these activities are not food or exercise related. In a longitudinal, two-armed controlled trial of 31 participants, the DSD intervention achieved a gradual and continuous weight loss with a statistically significant mean average of $2.6 \mathrm{~kg}$ loss over a 4week period, compared with $0.88 \mathrm{~kg}$ loss in the control group. Two months post-intervention, DSD participants had continued to lose weight with a total mean weight loss of $5.18 \mathrm{~kg}(S D=$ $3.85)$, compared with $0.43 \mathrm{~kg}(S D=1.94)$ loss in the control group $\left({ }^{47}\right)$; suggesting the changes effected in the DSD intervention were maintained.

A key finding in the study was a dose-response relationship between changes in behavioural flexibility that occurred as a result of the 4 week DSD program and the amount of weight loss observed. This supports the hypothesis that behavioural flexibility may facilitate in weakening poor lifestyle habits and therefore contribute to weight loss $\left(^{{ }^{5}}\right)$. 
Transforming Your Life (TYL) is an environmental modification approach to weight loss, which combines promoting healthy habits as well as disrupting unhealthy habits. Individuals were taught to create their personal food and exercise environment in a manner that minimises unhealthy eating and sedentary behaviour cues/choices, maximises healthy eating and exerciserelated cues/choices, and encourages automatic responding to goal-related cues ( ${ }^{(5)}$ ). In a 12week randomised controlled trial, 59 overweight and obese participants were randomised to either TYL or a weight loss program which emphasized reducing unhealthy relationship with food (New Perspectives [NP]). Despite equivalent weight loss at the end of treatment (Mean = $6.6 \mathrm{~kg}, S D=5.3$ ), the TYL participants were significantly more effective at maintaining their weight loss with a further average weight loss of $2.2 \mathrm{~kg}(S D=4.4)$ while NP participants regained an average of $2.1 \mathrm{~kg}(S D=7.3)$ during the 6-month no-treatment follow-up period $\left({ }^{(5)}\right)$.

Although a 6-month follow-up period is relatively brief, the continued weight loss in the TYL program supports the theory that habit-based interventions achieve greater success at maintaining weight loss long-term when compared to traditional behavioural weight loss programs $\left({ }^{23}\right)$.

\section{Limitations}

There are several limitations to this review. There is currently limited long-term follow up data on habit-based weight loss interventions; therefore this review reflects a maximum 6-month follow-up outcome. Weight loss outcomes at least 12-months post-intervention would provide a more accurate conclusion on the efficacy of habit-based interventions on long-term weight loss maintenance. We also did not discuss the physiological and biological effects on weight regain and obesity as we did not focus on causes of obesity. Rather, we focused on habit-based weight management interventions which may be effective for obesity treatment. The search strategy for this review restricted the search to habit-based interventions that focused specifically on habit-change as the conceptual theory. Although interventions may indirectly change an individual's habits, this study focused only on the interventions where habit-change was the primary strategy for behaviour change and therefore weight loss.

\section{Conclusion and areas for future research}

Ample evidence suggests that a significant part of daily eating behaviours consists of habits. In line with this, the concept of habit is increasingly incorporated into studies investigating the behavioural and psychosocial determinants of food choice, yielding evidence that habit is one of the most powerful predictors of eating behaviour and therefore weight loss success $\left.{ }^{36}\right)$.

Best intentions are not enough to elicit behaviour change. People with strong habits tend to continue their typical behaviour despite their well-meaning and often well-informed intentions ${ }^{28}$ In fact, theory and empirical research suggests that intentions guide actions largely when habits have not yet been formed ${ }^{(2)}$ This phenomenon supports the theory that habitual behaviour can be triggered independent of an individual's intentions $\left.{ }^{(58}\right)$. Therefore, a deeper 


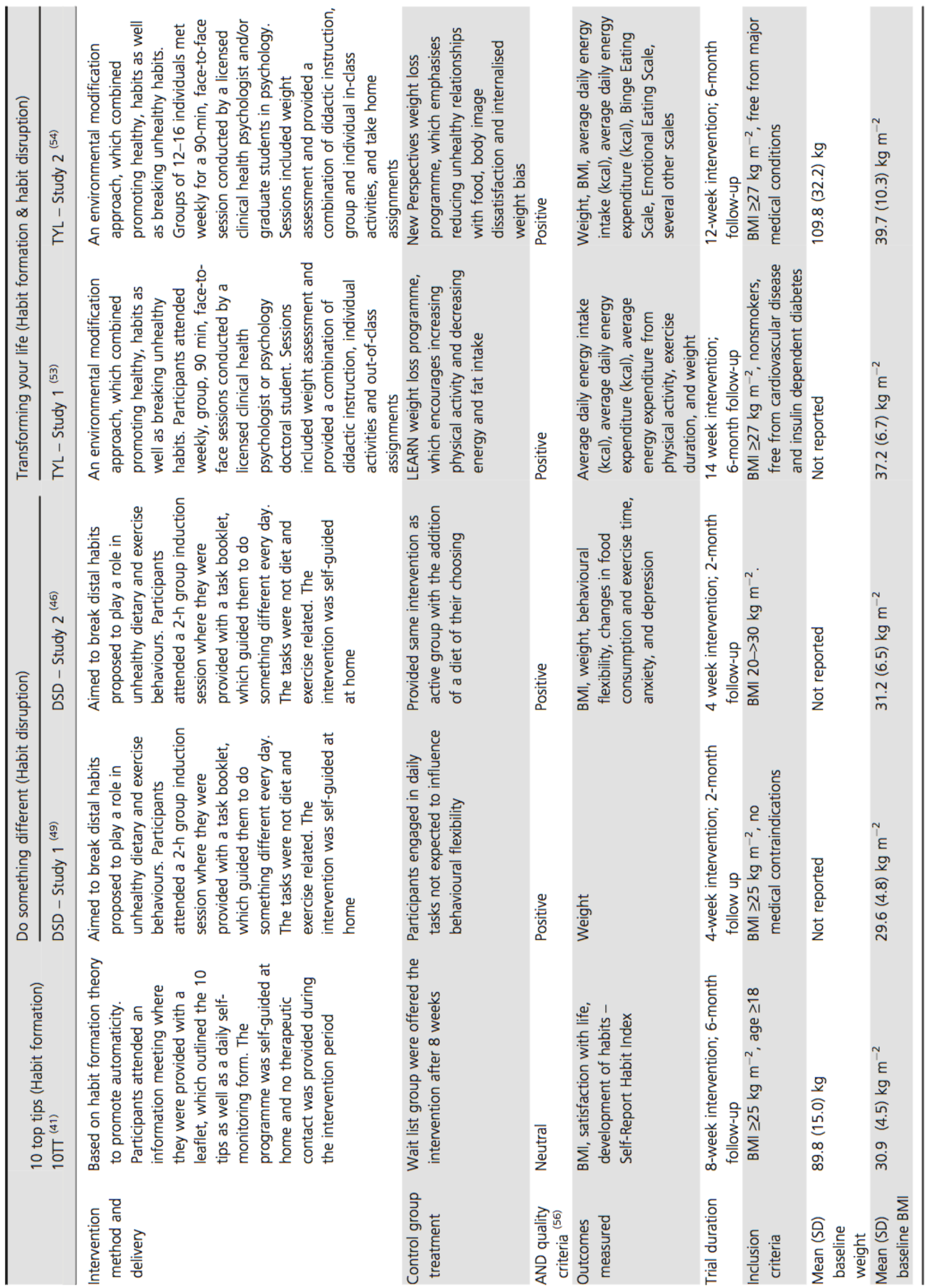




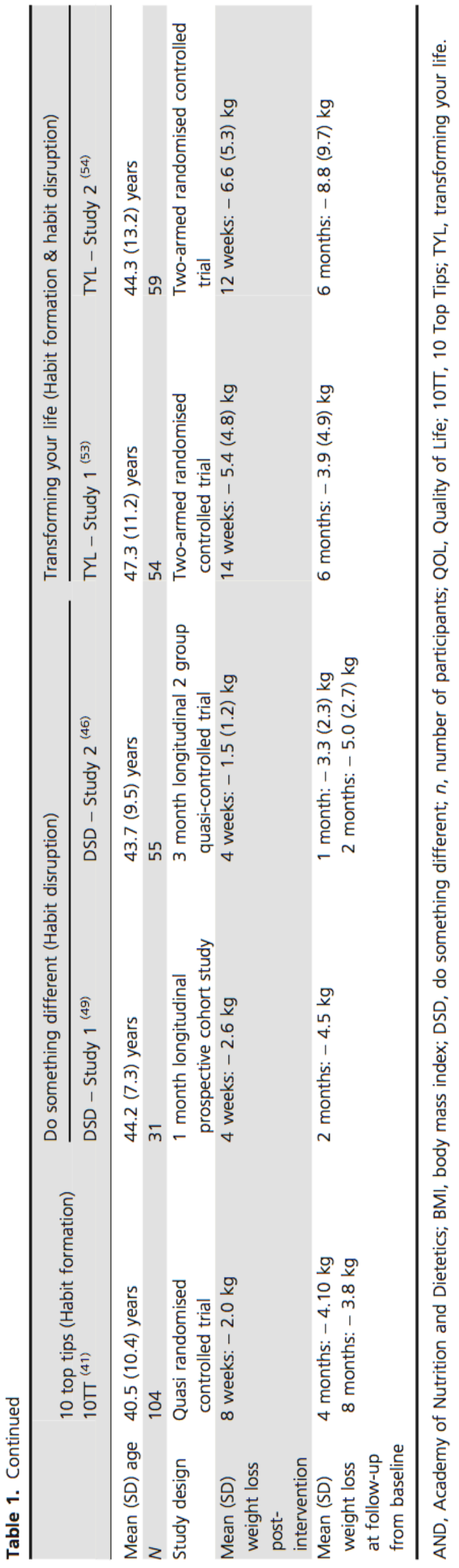

focus on habit-change interventions would be beneficial in order to better inform weight management interventions.

Despite using different methods, the habit-based interventions highlighted in this paper, namely 10TT, DSD and TYL all show significant weight loss results with promising long-term weight loss maintenance. None of the interventions however have published results regarding maintenance of the participants' weight loss longer than six months. For those who adhere to weight loss lifestyle programs, weight loss is often the outcome but typically not for long. Research in weight loss programs would benefit from long-term follow-up periods beyond the immediate and short-term.

Additionally, there is currently a dearth of studies focused primarily on habit-change theories for the treatment of obesity. Perhaps a fresh look at habits and the intention behaviour gap will shed some light on this significant problem.

Acknowledgments: The authors would like to thank Ms Ronel Erasmus and Dr Rebecca Beeken for their invaluable assistance on this project.

Disclosure Statement: The authors declare that there are no conflicts of interest. This research received no specific funding.

Transparency Declaration: The lead author affirms that this manuscript is an honest, accurate, and transparent account of the study being reported, that no important aspects of the study have been omitted and that any discrepancies from the study as planned have been explained. 


\section{References}

1. Roqué i Figuls M, Martinez-Zapata MJ, Pacheco R et al. Interventions for treating overweight or obesity in adults: an overview of systematic review (Protocol). The Cochrane Library. 2013(8).

2. Avenell A, Brown TJ, McGee MA et al. What are the long-term benefits of weight reducing diets in adults? A systematic review of randomized controlled trials. J Hum Nutr Diet. 2004;17:317-35.

3. Barte JC, ter Bogt NC, Bogers RP et al. Maintenance of weight loss after lifestyle interventions for overweight and obesity, a systematic review. Obes Rev. 2010;11:899-906.

4. Ash S, Reeves M, Bauer J et al. A randomised control trial comparing lifestyle groups, individual counselling and written information in the management of weight and health outcomes over 12 months. Int J Obes (Lond). 2006;30:1557-64.

5. Wing RR, Lang W, Wadden TA et al. Benefits of modest weight loss in improving cardiovascular risk factors in overweight and obese individuals with type 2 diabetes. Diabetes Care. 2011;34:1481-6.

6. Mertens IL \& Van Gaal LF. Overweight, obesity, and blood pressure: the effects of modest weight reduction. Obes Res. 2000;8:270-8.

7. Wing RR \& Hill JO. Successful weight loss maintenance. Annu Rev Nutr. 2001;21:32341.

8. Swencionis C, Wylie-Rosett J, Lent MR et al. Weight change, psychological well-being, and vitality in adults participating in a cognitive-behavioral weight loss program. Health Psychol. 2013;32:439-46.

9. Elfhag K \& Rossner S. Who succeeds in maintaining weight loss? A conceptual review of factors associated with weight loss maintenance and weight regain. Obes Rev. 2005;6:67-85. 10. Burns CM, Tijhuis MAR \& Seidell JC. The relationship between quality of life and perceived body weight and dieting history in Dutch men and women. Int J Obes (Lond). 2001;25:1386-92.

11. Heshka S, Anderson JW, Atkinson RL et al. Weight loss with self-help compared with a structured commercial program: a randomized trial. J Am Med. 2003;289:1792-8.

12. Wing RR, Phelan S. Long-term weight loss maintenance. Am J Clin Nutr. 2005;82:222-5. 13. Sobal J \& Bisogni CA. Constructing Food Choice Decisions. Ann Behav Med. 2009;38:37-46.

14. Cooper Z \& Fairburn CG. A new cognitive behavioural approach to the treatment of obesity. Behav Res Ther. 2001;39:499-511.

15. NIH Publication. Prescription medications for the treatment of obesity. Vital Health Stat 3. 2013.

16. Kwasnicka D, Dombrowksi S, White M et al. Theoretical explanations for maintenance of behaviour change: a systematic review of behaviour theories. Health Psychol Rev. 2016;6:277-96.

17. Baumeister RF, Masicampo EJ \& Vohs KD. Do conscious thoughts cause behavior? Annu Rev Psychol. 2011;62:331-61.

18. Nilsen P, Roback K, Brostrom A et al. Creatures of habit: accounting for the role of habit in implementation research on clinical behaviour change. Implement Sci. 2012;7:53.

19. Neal DT, Wood W \& Quinn JM. Habits-A Repeat Performance. Curr Dir Psychol Sci. 2006;15:198-202.

20. Gardner B. A review and analysis of the use of 'habit' in understanding, predicting and influencing health-related hebaiour. Health Psychol Rev. 2014;9:277-95. 
21. Neal DT, Wood W, Labrecque JS et al. How do habits guide behavior? Perceived and actual triggers of habits in daily life. J Exp Soc Psychol. 2012;48:492-8.

22. Quinn JA, Pascoe A, Wood W et al. Can't Control Yourself ? Monitor Those Bad Habits. Pers Soc Psychol Bull. 2009;36:499-511.

23. Gardner B, Lally P \& Wardle J. Making health habitual: the psychology of 'habitformation' and general practice. Br J Gen Pract. 2012;62:664-6.

24. Wood W, Quinn JM \& Kashy DA. Habits in everyday life: thought, emotion, and action. J Pers Soc Psychol. 2002;83:1281-97.

25. Wood W, Witt MG \& Tam L. Changing circumstances, disrupting habits. J Pers Soc Psychol. 2005;88:918-33.

26. Wansink B \& Sobal J. Mindless Eating: the 200 Daily Food Decisions We Overlook. Environ Behav. 2007;39:106-23.

27. Nilsen P, Roback K, Brostrom A et al. Creatures of habit: accounting for the role of habit in implementation research on clinical behaviour change. Implement Sci. 2012;7:53.

28. Danner UN, Aarts H \& de Vries NK. Habit vs. intention in the prediction of future behaviour: the role of frequency, context stability and mental accessibility of past behaviour.

Br J Soc Psychol. 2008;47:245-65.

29. Rothman AJ, Sheeran P \& Wood W. Reflective and automatic processes in the initiation and maintenance of dietary change. Ann Behav Med. 2009;38 Suppl 1:S4-17.

30. Sawkill S, Sparkes E, Brown K. A thematic analysis of causes attributed to weight gain: a female slimmer's perspective. J Hum NutrDiet. 2012;26(1):78-84.

31.Webb TL, Sheeran P \& Luszczynska A. Planning to break unwanted habits: Habit strength moderates implementation intention effects on behaviour change. Br J Soc Psychol.

2009;48:507-23.

32. Lally P \& Gardner B. Promoting habit formation. Health Psychol Rev. 2013;7:S37-S58.

33. Sniehotta F, Scholz U, Schwarzer R. Bridging the Intention-Behaviour Gap: Planning, Self-Efficacy, and Action Control in the Adoption and Maintenance of Physical Exercise.

Psych Health. 2005;20:143-160.

34. de Bruijn GJ. Understanding college students' fruit consumption. Integrating habit strength in the theory of planned behaviour. Appetite. 2010;54:16-22.

35. de Bruijn GJ \& Rhodes RE. Exploring exercise behavior, intention and habit strength relationships. Scand J Med Sci Sports. 2011;21:482-91.

36. Van't Reit J, Sijtsema SJ, Dagevos H et al. The importance of habits in eating behaviour. An overview and recommendations for future research. Appetite. 2011;57:585-96.

37.Gardner B, Abraham C, Lally P et al. Towards parsimony in habit measurement: Testing the convergent and predictive validity of an automaticity subscale of the Self-Report Habit Index. Int J Behav Nutr Phys Act. 2012;9.

38. Wiedemann AU, Gardner B, Knoll N et al. Intrinsic Rewards, Fruit and Vegetable Consumption, and Habit Strength: A Three-Wave Study Testing the Associative-Cybernetic Model. Appl Psychol Health Well Being. 2014;6:119-34.

39. Ji MF \& Wood W. Purchase and Consumption Habits: Not Necessarily What You Intend. J Consum Psychol. 2007;17:261-76.

40. Moldovan AR \& David D. Features of automaticity in eating behavior. Eat Behav. 2012;13:46-8.

41. Lally P, van Jaarsveld CHM, Potts HWW et al. How are habits formed: Modelling habit formation in the real world. Eur J Soc Psychol. 2010;40:998-1009.

42. Lally P, Chipperfield A \& Wardle J. Healthy habits: efficacy of simple advice on weight control based on a habit-formation model. Int J Obes (Lond). 2008;32:700-7.

43. Curioni CC \& Lourenco PM. Long-term weight loss after diet and exercise: a systematic review. Int J Obes (Lond). 2005;29:1168-74. 
44. de Bruijn GJ, Kroeze W, Oenema A et al. Saturated fat consumption and the Theory of Planned Behaviour: exploring additive and interactive effects of habit strength. Appetite. 2008;51:318-23.

45. Beeken RJ, Croker H, Morris S et al. Study protocol for the 10 Top Tips (10TT) trial: randomised controlled trial of habit-based advice for weight control in general practice. BMC Public Health. 2012;12:667.

46. Burke LE, Wang J, Sevick MA. Self-Monitoring in Weight Loss: A Systematic Review of the Literature. J Am Diet Assoc. 2011;111(1):92-102.

47. Fletcher BC, Hanson J, Page N et al. FIT - do something different: A new behavioral program for sustained weight loss. Swiss J Psychol. 2011;70:25-34.

48. Pine K, Fletcher B. Time to shift brain channels to bring about effective changes in health behaviour. Perspect in Public Health. 2014;134(1).

49. Fletcher BC \& Hanson J. A psychological weight loss intervention programme based on the FIT Framework. In: Division of Health Psychology. Br J Clin Psychol. 2004:67.

50. Fletcher B, Page N \& Pine K. A new behavioural intervention for tackling obesity: Do something different. Agro Food Industry Hi-Tech. 2007;18:8-9.

51. Page N, Fletcher B. FIT Science for weight loss - A controlled study of the benefits of enhancing behavioural flexibility. Agro Food Ind Hi-Tech. 2008;19(5):8-9.

52. Fletcher B, Pine KJ. Flex : Do Something Different. Chicago: University Of Hertfordshire Press; 2012.

53. Webb TL \& Sheeran P. Does changing behavioral intentions engender behavior change? A meta-analysis of the experimental evidence. Psychol Bull. 2006;132:249-68.

54. Carels RA, Young KM, Koball A et al. Transforming your life: an environmental modification approach to weight loss. J Health Psychol. 2011;16:430-8.

55. Carels RA, Burmeister JM, Koballm AM et al. A randomized trial comparing two approaches to weight loss: Differences in weight loss maintenance. J Health Psychol. 2014;19:296-311.

56. Lally P, Wardle J \& Gardner B. Experiences of habit formation: A qualitative study. Psychol, Health Med. 2011;16:484-9.

57. Academy of Nutrition and Dietetics. Evidence Analysis Manual: Steps in the Academy Evidence Analysis Process. Quality Criteria Checklist: Primary Research. Chicago, USA. 2012.

58. Wood W, Quinn JM, Kashy DA. Habits in everyday life: thought, emotion, and action. J Pers Soc Psychol. 2002;83(6):1281-1297. 